Article

\title{
A Comparison of Female Delinquents: The Impact of Child Maltreatment Histories on Risk and Need Characteristics among a Missouri Sample
}

\author{
Anne Dannerbeck-Janku ${ }^{1, *, \dagger}$, Clark Peters ${ }^{2, \dagger}$ and Jacob Perkins ${ }^{3}$ \\ 1 Missouri Office of State Courts Administrator, PO Box 104480, Jefferson City, MO 65110, USA \\ 2 School of Social Work, University of Missouri-Columbia, 719 Clark Hall, Columbia, MO 65211, USA; \\ E-Mail: peterscm@missouri.edu \\ 3 Brown School of Social Work, Washington University in St. Louis, Campus Box 1196, One \\ Brookings Drive, St. Louis, MO 63130, USA; E-Mail: jacobperkins84@gmail.com \\ $\dagger$ These authors contributed equally to this work. \\ * Author to whom correspondence should be addressed; E-Mail: Anne.Janku@courts.mo.gov; \\ Tel.: +1-573-751-4377.
}

External Editor: Tamar R. Birckhead

Received: 1 August 2014; in revised form: 3 October 2014 / Accepted: 15 October 2014 /

Published: 31 October 2014

\begin{abstract}
While boys who offend have been a dominant majority and primary concern of the juvenile court since its earliest days, the population of delinquent girls has increased in recent years at a far higher rate in the U.S. The special challenges presented by females, however, continue to be generally overlooked by the justice system. Moreover, while a few specialized programs now serve these girls, the field tends to view young female offenders as a homogeneous group; what distinguishes particular female subpopulations and the characteristics associated with different criminal trajectories have gone largely unexplored. Employing data from the state of Missouri, this study examines girls who offend, identifying models that predict subsequent violent behavior that include indicators such as parental substance abuse and incarceration, and offender substance abuse, mental health, and school behavior. Special attention is given to the effects of child maltreatment, which we find significantly, but weakly correlated with violent behavior. The authors conclude by considering the possibility that maltreatment may be correlated with other criminogenic factors, and by discussing the implications of findings for future research and practice,
\end{abstract}


especially services that take into account the trauma experienced by young women who come to the attention of state authorities.

Keywords: delinquency; juvenile justice; child maltreatment; crossover youth; gender; risk factors; Missouri

\section{Introduction: Female Delinquency}

Since its earliest days, the juvenile court had distinct legal frameworks for dealing with children who offend and children who were abused, neglected, and dependent [1]. Even as the early court pioneers recognized family dysfunction was at the heart of its work for a majority of its wards, the presenting legal framework dictated - and foreclosed — some service options. Moreover, the system tended to treat girls and boys who offended differently from its start; young women were brought to court for distinct offenses, faced different personnel, and had fewer service options [2,3].

Contemporary juvenile courts and human service systems still struggle to give adequate attention and resources to girls who are drawn into the juvenile justice system. While the population of female delinquents continues to be substantially lower than that of males, the number of female delinquents is increasing at a faster rate than that of male delinquents [4]. In recent decades, the smaller population of females has continued to make it a lower priority in research and in developing intervention practices [5,6]. However, since the 1992 reauthorization of the Juvenile Justice and Delinquency Prevention Act of 1974, an enhanced focus (as well as more funding) has been directed toward female-specific programming. Nevertheless, the federal effort to improve the response to young women offenders still has failed to identify the unique features of female delinquency. Female delinquents account for a high proportion of adult female crimes overall [7]. Violent, chronic female delinquents are more likely to become adult offenders than their male counterparts [8] and have more severe adulthood outcomes in comparison to females with limited and less violent delinquent histories [9]. Given this evidence, identifying risk factors and pathways to criminal outcomes and better meeting the needs of young women is critical [10].

\subsection{Gender Difference}

As with research and practice, the development of theories of delinquency has been male-centered [6,11]. Given the clear gender differences that emerge when examining delinquent behavior, the applicability of these theories to female delinquents is generally untested and dubious. For instance, in assessing the types of delinquent behaviors that distinguish youth by gender, across all age groups for person, property, drug, and public order offenses from 1985 to 2010, case rates for males exceed rates for females, however, since the late 1990s female rates for person and drug offenses increased, while male rates leveled off [4].

Another reason for considering that female delinquents may be different than males is that the rates of female involvement in delinquency have been increasing at faster rates than for males. One indicator of particular concern is the change in the violent crime arrest rate. The female rate has been converging 
with the male rate since the 1980 s. For instance, during the 1980 s, the male violent crime arrest rate was nearly 8 times greater than the female rate, however, by 2011, this disparity had been cut in half [12]. The public has a perception, backed by these statistics, that females are becoming more violent. Research has shown that violent youth are likely to become violent adults [9].

Complicating the interpretation of these statistics is the fact that arrest increases do not necessarily mean that delinquency is increasing; it may be that policy changes are having an impact on enforcement and that laws are changing. Society is also changing how it responds to certain behaviors. Indeed, at least to some extent, that is the case. For instance, domestic violence and family problems are now viewed in the context of assault and all parties involved in a domestic dispute can be arrested [13]. Females are more likely to be arrested for violent crimes when in the past they may have been treated for status offenses or only the male or adult perpetrator of a domestic dispute was arrested [14].

A final reason for considering that female delinquents may differ from males in important ways is that lessons from the substance abuse intervention field clearly demonstrate that gender-specific intervention is necessary and more effective than gender neutral treatment $[15,16]$. Thus, even without a strong theoretical base from which to build intervention models, experience from other fields strongly indicates that gender-specific intervention will best serve the needs of young women involved in delinquent behavior.

More attention should be drawn to the group of young female offenders with an assault charge since research indicates that female adolescents who are violent tend to grow into violent adults [7]. A high proportion of females have status allegations. When placed in the context of the relational aspect of young women's lives, these offenses can be interpreted as indicative of a breakdown in relationships at school (truancy) and with parents (beyond parental control) [12,17]. They can also be interpreted from the standpoint of a differential standard for male and female behavior. Females are generally more closely monitored and controlled than males because of perceived greater vulnerability stemming from societal constructions of femininity [18-20]. Thus, comparable behavior (out of control per se) may be perceived differentially as a problem behavior in females and males.

In examining delinquent and criminal history, as with most such studies, it should be remembered that while the youth may be adjudicated for one allegation, they may have committed other, undetected acts of delinquency as well. Without information on all such acts, it is not possible to come to any general conclusions about the gendered nature of delinquent behavior. The lack of a clear pattern of entry into the criminal justice system among young women (in comparison to the peak at age 12 for males) suggests that many more pathways, not all of them developmental, may lead to female delinquency. A developmental model, relating age specific tasks and needs may not be appropriate for understanding young women's behavior. Or it may be that different developmental tasks and needs will help understand female delinquent behavior.

\subsection{Gendered Risk and Response}

Other research has documented the greater likelihood that females are more often the victims of abuse and neglect than males [21]. Much has been discussed in the literature over the last several years about the important role of parenting in moderating adverse life events [22]. Some research has also suggested that males and females may be parented differently [23]. Substance abuse is often closely tied to 
delinquency and criminal behavior [24]. Some research indicates that young women begin drug use as a way to cope with emotions resulting from trauma and abuse. Research has suggested that different standards are applied to males and females, and lesser maladaptive behaviors are interpreted and responded to more severely in females [25].

The level of certain risk factors, namely physical and sexual abuse and mental illness, seems to be higher in female delinquents than male [26]. Females are more likely to be physically and sexually abused [21]. Some researchers (see [27]) have explained delinquent behavior in females as an adaptive response to abuse. According to the Rochester study, by age 18, ten percent of male and 27 percent of female delinquents had substantiated maltreatment cases [28]. Females who have been victims of abuse and neglect are more likely to be arrested for violence than are young men [29]. Sexual abuse victims (of whom the majority are women) tend to be more aggressive than non-abuse victims [30]. Besides being more aggressive, abuse victims tend to be runaways (protective response) [31] and to abuse substances (emotion focused coping).

Another constellation of risk factor differences centers on family relations. Female delinquency is more strongly related to these family-level variables than is male delinquency [32,33]. Female delinquents tend to have more relationship problems than males [28]. They are more likely to normalize domestic violence. Children who witness domestic violence tend to use deceptions and lying as protective mechanisms to avoid physical harm or to protect both victims and perpetrators of the violence. Children who have witnessed domestic violence grow up to experience low self-esteem, depression, and anxiety. They tend to be more aggressive [34]. Aggressive tendencies are exhibited not only in physical behavior but also in relationships. Female delinquents are more likely to exhibit relational aggression, an indirect form of aggression. They may harm others through manipulation or damage to their peer relationships (e.g., spreading rumors) [35]. They are more likely to come from a broken home. They tend to have experienced more disruptions [36]. One major life disruption for a child is parental incarceration. Female delinquents are more likely than males to have had a family member locked up [37]. The associations between such disruptions and a greater tendency toward delinquency in females suggest some gender related differences in how disruptions are processed and the responses of youth to them [38].

\subsection{Maltreatment and Female Delinquency}

The purpose of this study is to better understand the characteristics and behaviors of young women involved in the justice system as both victims of child maltreatment and as perpetrators of juvenile offending behaviors. Previous research on crossover youth in the State of Missouri indicated that among over 79,000 referred youth in Missouri courts over the period from 2002 to 2009, 17 percent had a child abuse history and were thus labeled as youth who had crossed over from the child welfare system to the delinquency system. Compared to youth without the maltreatment history, these crossover youth have more severe risk indicators related to mental health, social environment, and justice system history. Of deep concern, they also are more likely to engage in violent behaviors [39]. While a number of studies have noted that a disproportionate numbers of females crossover from maltreatment to delinquency, very little research has actually examined females who crossover and compared them to other female delinquents. Thus, the present study compares the risk and need characteristics for all young women with and without a prior child maltreatment history who had a juvenile delinquency or status referral in 
Missouri for 2010. To this end, the study poses two research questions: (a) Do the risk and need profiles of delinquent females with a maltreatment history differ significantly from non-maltreated female delinquents? (b) Do female crossover youth differ from non-crossover females in their likelihood of behaving violently?

\section{Methodology}

The data used to identify crossover youth are from the Missouri judicial data system (called the Justice Information System or JIS). For a legally sufficient status or law referral, a statewide risk assessment is required by Missouri Statutes (Subsection 4 and 5, Section 211.326.1, RSMo. Supp. 1995) and recorded in the JIS. These assessments are designed to collect information on youth personal history of involvement with the justice system (as a victim and perpetrator), mental health issues, and social environment influences associated with risks to reoffend. A risk assessment committee (comprised of representatives from the Missouri Juvenile and Family Courts, Missouri Division of Youth Services, and the Missouri Juvenile Justice Association) developed a consensus-based juvenile offender classification system that included a risk assessment. The risk assessment was refined through a risk assessment validation study and two subsequent revalidations [40-42] using well-established validity criteria. These criteria include: progressively higher recidivism rates at each risk level, maximum separation between risk levels, and a clear distinction between risk levels in terms of recidivism [43]. Reliability is ensured through frequent training sessions on the assessment tool for new and continuing juvenile office staff.

Risk assessments are conducted through a face-to-face structured interview between juvenile office staff and the youth with a parent(s) or caregiver(s) present. The Office of State Courts Administrator provided training on the structured instruments to juvenile officers, who guide case prosecution, and other court staff to enhance the consistency and accuracy of the measurements taken during the interview. Information from the interviews is crosschecked with official records. When conflicts occur, information from official records is used.

Variables obtained from the juvenile offender risk and needs assessments and related to offenses are briefly described below by category. More detailed information, such as assessment forms, definition of risk and needs factors, and questionnaires for the structured interviews, can be found in the user manual provided by the Office of State Courts Administrator [44].

\subsection{Maltreatment Indicator}

The purpose of this study is to determine if certain risk factors, including maltreatment are associated with violent offending. To determine whether a youth has a history of child abuse/neglect (dichotomous variable for history or not), juvenile officers examine Children's Division or juvenile court records accessed through the Missouri Juvenile Justice Information System, a statewide database with information from a range of state agencies. They look for official records for the child with a finding of Probable Cause indicating abuse or neglect. Or, they look for petitions filed in juvenile or family court for abuse or neglect. When such a petition is filed even if it is dismissed without prejudice, it is counted as indicating a history of maltreatment. In the rare instances when they cannot access information from the state system, mainly because the child is from another state, self-reported information is used. 


\subsection{Violence Indicator}

In Missouri, violent offenses are those in which "the offender recklessly or knowingly inflicts, or intends to inflict, or threatens serious physical injury or death" ([44], pp. 2-8). Assault history, which will be the dependent variable for violent behavior in the multivariate analysis, includes both present and past assault charges. The original response set included no assault referrals, one or more misdemeanor assaults, and one or more felony assaults. The two assault categories were collapsed into one general indicator of violent offenses. Offenses categorized as assaults in the User Manual include homicides, sexual assaults, robbery, general assault, arson, and kidnapping. Official court records provide this information. Any reported history of child abuse/neglect is presumed to have occurred prior to any assault behaviors although this assumption cannot be verified with this cross-sectional data set.

\subsection{Mental Health and Associated Risk Indicators}

Categorical variables cover mental health history and problems with externalizing behavior, substance abuse, learning disorders, interpersonal skill levels, school attendance or discipline, and academic performance as well as substance abuse history. The information is obtained through a structured interview. The youth are asked if they have ever received a diagnosis from a mental health professional (excluding learning disorders, conduct disorders, and substance abuse) and if they have received treatment for the disorder. In assessing behavior problems (none, moderate, severe), other than the self-reported information, officers make a determination based on information related to significant behavior problems at home or school and information from previous referrals, particularly for assault. Substance abuse is assessed by asking parents a series of questions based on tangible behavioral markers regarding substance use and associated behaviors. Then the youth are asked a series of questions regarding substance use patterns and interaction of substance use and other behavior problems. From this information, the assessor determines into which of three categories (none, moderate, severe substance abuse problems) a youth falls. A reading, mathematics or written expression disorder diagnosis indicates a learning disorder. School behavior problem level (none, moderate, severe) is measured through referrals for truancy, out-of-school suspensions, expulsions, or multiple unexcused absences. Academic performance (passing, below average, failing) is scored based on grades obtained from school when available or by asking the youth what his/her grades are. Attitude is one of the more subjective factors assessed. It is derived from a series of 15 questions about trust, role of authority figures, impressions of the court proceedings, and level of empathy. The assessor compares the responses to descriptions of three categorical responses (motivated, uncooperative, negative) to identify which one best fits the youth. An interpersonal skill level (good, moderate or severely impaired) is identified from a series of ten questions about the nature of the youth's friendships.

\subsection{Social Environment Indicators}

An additional set of variables measures the social environment influence of parents, peers and social support systems. Parent management style is classified based on effectiveness. Effective parent style indicates that structure, support and supervision are consistent and appropriate. Moderately ineffective style indicates lack of consistent and appropriate supervision and guidance. Severely ineffective style 
indicates a total lack of any discipline, guidance, or structure. To operationalize these categories, the interviewer asks the youth 13 questions about parent involvement, family routines, parental monitoring, and consistency. Yes/no responses are elicited for queries about family activities, routines, chores, parent monitoring, curfews, parent acquaintance with friends, parent alcohol use, use of rewards and punishments, and fairness. They are asked for frequency of punishment follow through and of parent agreement on discipline. A more open-ended question is asked regarding how the youth describe their parents, especially how strict they are. From their responses, the evaluator makes a subjective determination regarding which of the three levels of effectiveness best described the effectiveness of the parents' management style.

Youth and parents are asked if the parent(s) has ever been diagnosed with a mental disorder, and if either of them has ever been incarcerated. The parent(s) are further queried about their substance abuse history. To assess peer relationships and their influence (neutral, negative, strongly negative), youth are asked 21 questions about their friends and court contacts, positive and negative behaviors, dating, parent's impressions of friends, and specific activities including gang affiliations. Those rated as having strong negative influence had a primary contact group heavily involved in delinquent activities, frequent court contacts and gang membership. To gauge social support, youth are asked seven questions about positive influences from good role models in their lives as well as negative influences from someone involved in criminal activities. The responses are distinguished by the presence, consistency, and strength of positive and negative role models and categorized by the juvenile officer into one of the four levels: strong and stable social support with positive role models, limited support system with one positive role model, weak support system with no positive role models, and highly unstable support system with criminal influence.

\subsection{Justice System Involvement}

For personal history of involvement with the justice system, the juvenile officer examines past records for the age at first referral and number of prior referrals. A dichotomous variable was created for information on the juvenile's out-of-home placement history which would include any stay in a government operated or private residential facility.

A demographic variable for race/ethnicity is also included in the analysis. The racial categories include Caucasian, African-American and "Other", which includes 24 Asian, 11 Native American, and 103 Hispanic females.

\subsection{Analytic Plan}

The study group consists of 5737 females who had at least one status or delinquency referral case and at least one risk assessment recorded in 2010 in the Missouri court database, the Justice Information System. If multiple assessments exist for a youth, the most recently entered record was kept in order to capture the most updated information for the youth. We use this study group to test the hypothesis that significant differences exist between females with and without a history of child maltreatment in their tendency toward violent behavior and risk factors for reoffending. The Chi-Square tests were conducted to identify significant risk and needs factors associated with the crossover youth. In addition, we examine 
the relationship between violent behaviors and crossover status while controlling for other risk factors in a logistic regression model.

\section{Results}

Among the 5737 young women with referrals, 1256, or 22 percent, had a child maltreatment history. This proportion is considerably higher than the 17 percent in the study of the combined male and female group in the previous Missouri study. Next we will examine patterns of differences for the crossover and non-crossover females for groups of risk factors associated with personal history, mental health, and social environment.

While parents are not the only individuals who may be found to have maltreated a child, certain parent characteristics are associated with maltreatment. Parents with mental health issues and substance abuse problems may have impaired cognitive functioning. As a consequence they may not be able to parent effectively. Parent management style reflects parent supervision and responsiveness to a child's needs. Parenting practices have a significant impact on antisocial behavior in children and can even affect the child's propensity to engage in violent behavior [45]. Parental incarceration is associated with ineffective parenting, child maltreatment, and violent behavior in youth [46].

As the Table 1 indicates, the young women who have crossed over from child abuse/neglect to delinquency have parents with significantly worse indicators on all the relevant characteristics.

Table 1. Variable frequency and crosstabs for crossover female youth $(\mathrm{N}=5737)$.

\begin{tabular}{|c|c|c|c|}
\hline Variables & Description & \multicolumn{2}{|c|}{$\mathbf{N}(\%)$} \\
\hline \multirow[t]{2}{*}{ Child maltreatment history } & none & \multicolumn{2}{|c|}{$4481(78)$} \\
\hline & child maltreatment history & \multicolumn{2}{|c|}{$1256(22)$} \\
\hline \multirow[t]{3}{*}{ Demographics } & & \% within & \% within \\
\hline & & Non-crossover & crossover \\
\hline & & $N=4481$ & $N=1256$ \\
\hline \multirow[t]{3}{*}{ Race } & Caucasian & $78.5 \%$ & $80.4 \%$ \\
\hline & African American & $18.8 \%$ & $18.2 \%$ \\
\hline & Other & $2.7 \%$ & $1.4 \%$ \\
\hline \multicolumn{4}{|l|}{ Personal History } \\
\hline \multirow[t]{3}{*}{ Assault history *** } & none & $78 \%$ & $66.5 \%$ \\
\hline & one or more misdemeanor assaults & $20.6 \%$ & $31.1 \%$ \\
\hline & one or more felony assaults & $1.4 \%$ & $2.5 \%$ \\
\hline \multirow[t]{3}{*}{ Age at 1 st referral $* * *$} & 12 and under & $23.5 \%$ & $43 \%$ \\
\hline & 13 to 15 & $58.2 \%$ & $49.8 \%$ \\
\hline & 16 or above & $18.3 \%$ & $7.2 \%$ \\
\hline Prior referral $* * *$ & none & $53 \%$ & $26 \%$ \\
\hline (status or law) & one or more & $47 \%$ & $74 \%$ \\
\hline \multirow[t]{2}{*}{ Out-of-home *** } & none & $86.7 \%$ & $36.1 \%$ \\
\hline & prior out-of-home placement & $13.3 \%$ & $63.9 \%$ \\
\hline
\end{tabular}


Table 1. Cont.

\begin{tabular}{|c|c|c|c|}
\hline \multirow{2}{*}{$\begin{array}{l}\text { Variables } \\
\text { Social Environment }\end{array}$} & \multirow[t]{2}{*}{ Description } & \multicolumn{2}{|c|}{$\mathbf{N} \%$} \\
\hline & & & \\
\hline \multirow[t]{2}{*}{ Parental mental health $* * *$} & none & $89.6 \%$ & $60 \%$ \\
\hline & parental mental disorder & $10.4 \%$ & $40 \%$ \\
\hline \multirow[t]{2}{*}{ Parental substance abuse $* * *$} & none & $87 \%$ & $56.9 \%$ \\
\hline & parental substance abuse & $12.9 \%$ & $43.1 \%$ \\
\hline \multirow[t]{2}{*}{ Parental incarceration $* * *$} & none & $80.6 \%$ & $46.2 \%$ \\
\hline & parental prior incarceration & $19.4 \%$ & $53.8 \%$ \\
\hline \multirow[t]{3}{*}{ Parental management style $* * *$} & effective & $45 \%$ & $19 \%$ \\
\hline & moderately ineffective & $44.7 \%$ & $46.6 \%$ \\
\hline & severely ineffective & $10 \%$ & $34.4 \%$ \\
\hline \multirow[t]{3}{*}{ Peer influence $* * *$} & neutral & $44.9 \%$ & $32.6 \%$ \\
\hline & negative & $48.4 \%$ & $50.3 \%$ \\
\hline & strong negative & $6.7 \%$ & $17 \%$ \\
\hline \multirow[t]{4}{*}{ Social support system $* * *$} & strong support system & $48.8 \%$ & $25.3 \%$ \\
\hline & limited support system & $41.8 \%$ & $46.3 \%$ \\
\hline & weak support system & $8.6 \%$ & $23.8 \%$ \\
\hline & $\begin{array}{l}\text { strongly negative/criminal } \\
\text { influence }\end{array}$ & $0.8 \%$ & $4.6 \%$ \\
\hline \multicolumn{4}{|l|}{ Mental Health Related Issues } \\
\hline \multirow[t]{3}{*}{ Mental health $* * *$} & no disorder & $84 \%$ & $55.7 \%$ \\
\hline & disorder with treatment & $13.8 \%$ & $37.8 \%$ \\
\hline & disorder with no treatment & $2 \%$ & $6.5 \%$ \\
\hline \multirow[t]{2}{*}{ Learning disorder $* * *$} & none & $93.6 \%$ & $84.1 \%$ \\
\hline & diagnosed disorder & $6.4 \%$ & $15.9 \%$ \\
\hline \multirow[t]{3}{*}{ Interpersonal skills $* * *$} & good skills & $68.7 \%$ & $45.6 \%$ \\
\hline & moderately impaired skills & $29.6 \%$ & $47 \%$ \\
\hline & severely impaired skills & $1.7 \%$ & $7.4 \%$ \\
\hline \multirow[t]{3}{*}{ Substance abuse problem $* * *$} & none & $81.2 \%$ & $70.7 \%$ \\
\hline & moderate & $17.1 \%$ & $24.1 \%$ \\
\hline & severe/dependence & $1.7 \%$ & $5.2 \%$ \\
\hline \multirow[t]{3}{*}{ Academic performance $* * *$} & passing without difficulty & $59.5 \%$ & $39.4 \%$ \\
\hline & functioning below average & $30 \%$ & $40.4 \%$ \\
\hline & failing & $10.5 \%$ & $20.1 \%$ \\
\hline \multirow[t]{3}{*}{ Behavior problem $* * *$} & none & $45.9 \%$ & $20.8 \%$ \\
\hline & moderate & $45.4 \%$ & $53.9 \%$ \\
\hline & severe & $8.7 \%$ & $25.3 \%$ \\
\hline \multirow{3}{*}{$\begin{array}{l}\text { School problems } * * * \\
\text { (attendance \& discipline) }\end{array}$} & none or minor problem & $49.9 \%$ & $31.8 \%$ \\
\hline & moderate & $39.4 \%$ & $44.2 \%$ \\
\hline & severe & $10.7 \%$ & $24 \%$ \\
\hline \multirow[t]{3}{*}{ Attitudes $* * *$} & motivated to change & $69.2 \%$ & $45.8 \%$ \\
\hline & uncooperative/unmotivated & $26.8 \%$ & $41.8 \%$ \\
\hline & $\begin{array}{l}\text { very negative/resists } \\
\text { change }\end{array}$ & $4 \%$ & $12.4 \%$ \\
\hline
\end{tabular}

Note: $* * *$ indicates Chi Square statistic significant at $p<0.001$ for crossover $v s$. non-crossover. 
While parents certainly play a key role in the development of a child, other family and community members can also influence a child. Caring adults and supportive peers can help a child cope with trauma. Inadequate interpersonal relationships on the other hand, can lead a child to behave in an antisocial manner and even resort to violence to cope with stress and trauma. In addition, relationships seem to play an even larger role in the life of girls than of boys [47].

The crossover females in this group differ significantly on all social environment factors from their counterparts. While the proportions who have the most negative or severe levels are not as large as for the parent characteristics, nevertheless, these young women tend to lack the kinds of positive supports that would help them overcome violence exposure and trauma in their lives.

A significant proportion of female delinquents have mental health needs. Crossover youth often suffer from trauma resulting from their maltreatment or removal from their family of origin. The maltreatment seems to affect females more deeply than males, and for longer periods [48].

The risk and needs assessment process includes a number of factors related to mental health. Significant differences exist on all these factors for the crossover females. While female delinquents generally have high rates of substance use, a significantly larger proportion of the crossover females have severe problems. Almost 38 percent have been treated for mental health issues and another 6.5 percent have identified but untreated needs. Some of the most significant areas of difference lie in the large proportion of crossover females who have both behavior problems and school discipline problems, the majority of the crossover group have serious problems in both areas of functioning. Such behavior problems are often indicative of mental health needs.

To test whether a history of child maltreatment would have a significant impact on the likelihood to have engaged in violent behavior, we conducted a logistic regression on a subsequent assault referral, controlling for demographic, risk, and need factors. Violent offense history was the response variable, with "1" denoting a girl with one or more prior/present referrals for a misdemeanor or felony violent offense. We collapsed the categories to two for all variables except age at first referral, which could be objectively assessed. The other categorical variables differed by degree of severity and were somewhat more subjective in nature. The model was originally run with all categories for the included variables, and the results were compared to the version with the collapsed variables. Comparing the two models, we found no differences in the direction or significance of the impacts. Table 2 provides the significant regression results from a stepwise selection. The model satisfied the Hosmer and Lemeshow goodness-of-fit test. The multicollinearity diagnostic statistics from ordinary least squares regression were tested; namely the variance inflation factor. No variance inflation factor (VIF) for any explanatory variable exceeded 10 in the regression, indicating the absence of unacceptable multicollinearity [49].

The logistic regression results showed that a history of child maltreatment is a significant factor in predicting a tendency toward violence but the effect is not very strong. The young women with a history of maltreatment had 1.184 increased odds of receiving one or more violent offense referrals when all other factors were controlled. Being Caucasian had 1.62 times the odds of a violent offense referral compared to African American females. The younger the age at the time of the first referral to the juvenile office for a status or delinquency offense, the more likely the girl is to have a violent offense referral. Having an out-of-home placement history or a prior referral decreases the odds of having a violent offense referral. 
Table 2. Logit estimates of significant effects on violent offense history for female offenders.

\begin{tabular}{|c|c|c|c|}
\hline \multicolumn{2}{|l|}{ Parameter } & \multirow{3}{*}{$\begin{array}{c}\begin{array}{c}\text { Odds } \\
\text { Ratio }\end{array} \\
1.621 * * *\end{array}$} & \multirow{3}{*}{$\begin{array}{c}\mathbf{9 5 \%} \\
\text { CI } \\
(1.390,1.889)\end{array}$} \\
\hline & & & \\
\hline \multirow{2}{*}{\multicolumn{4}{|c|}{ Personal History }} \\
\hline & & & \\
\hline Child maltreatment & Yes $=1 v s$. No & $1.184 *$ & $(0.995,1.410)$ \\
\hline Out-of-home placement & Yes $=1 v s$. No & $0.712 * * *$ & $(0.603,0.841)$ \\
\hline Prior referrals & Yes $=1 v s$. No & $0.416 * * *$ & $(0.353,0.490)$ \\
\hline \multirow[t]{4}{*}{ Age at first referral } & Age $15=1 v s$. age 16 & $1.647 * * *$ & $(1.258,2.157)$ \\
\hline & Age $14=1$ vs. age 16 & $1.911 * * *$ & $(1.458,2.507)$ \\
\hline & Age $13=1$ vs. age 16 & $2.422 * * *$ & $1.825,3.216)$ \\
\hline & Age 12 or younger $=1 v s$. age 16 & $2.932 * * *$ & $(2.182,3.939)$ \\
\hline \multicolumn{4}{|l|}{ Mental Health Issues } \\
\hline Juvenile mental health status & Mental disorder $=1 v s$. No & $0.616 * * *$ & $(0.526,0.722)$ \\
\hline Juvenile substance abuse & Substance abuse problem $=1 v s$. No & $1.212 *$ & $(1.030,1.426)$ \\
\hline Juvenile school behavior & Moderate problem $=1 v s . \mathrm{No} /$ minor & $0.854 *$ & $(0.736,0.991)$ \\
\hline Juvenile behavior problem & Behavior problem $=1 v s$. No/minor & $0.612 * * *$ & $(0.519,0.722)$ \\
\hline \multicolumn{4}{|l|}{ Social Environment } \\
\hline Parental prior incarceration & Yes $=1 v s$. No & $0.827 *$ & $(0.712,0.960)$ \\
\hline Parent mgmt. effectiveness & Ineffective parenting $=1 v s$. effective & $1.167 *$ & $(0.995,1.368)$ \\
\hline
\end{tabular}

Note: $* p<0.05 ; * * * p<0.001$.

Among the mental health factors that are significant, only having a substance abuse problem increases the odds of a violent offense referral. Having mental health problems, school behavior problems, or general behavior problems decreases the likelihood of a violent offense referral. Among social environment factors, a parental history of incarceration decreases the odds of an assault referral and an ineffective parent management style increases the odds.

\section{Implications for Policy, Programming and Practice}

One of the key challenges of discerning how best to address the issues of young women offenders, and especially those who have evidence of maltreatment, is identifying the relevant correlates of subsequent misbehavior and disentangling the relevant individual characteristics from the institutional responses that may contribute to recidivism. Historical and contemporary evidence shows us that child welfare agencies and dependency courts handle cases very differently than do delinquency courts and probation departments. Within this policy and practice context, the particular challenges presented by delinquent girls have often been neglected. Moreover, when females have been given attention by policymakers and practitioners, they have been typically seen as a homogenous group, alike in their dissimilarity to boys. The study presented in this article is a first step toward unpacking female offending, identifying particular subgroups of individuals relevant for policy and practice, and understanding the nature of the nexus between child welfare and delinquency for girls who offend.

Our findings indicate that a history of child maltreatment is significantly associated with violent behavior for girls. However, other factors - including race and early offending careers - show a stronger association with assault referrals. While this finding suggests that maltreatment may not be a strong 
predictor for young women, we also found that those in our sample who have a history of maltreatment are more likely than their peers to indicate other troublesome characteristics, including mental illness, substance abuse, and parental mental illness and incarceration, though we found that these characteristics themselves are not associated with assault referrals. These findings may explain why the child maltreatment indicator was not more robust; the correlation with other indicators that other studies show to be associated with delinquency may dilute the coefficient's value. In other studies, scholars have found that the effects of race, poverty, and child welfare involvement to be difficult to distinguish and easily confounded [50,51], and the comorbidity of delinquency with emotional and learning impairment makes disentangling the effects of each difficult [52]. The role of caregiver attachment may also require further exploration for this population [53]. Ultimately, researchers exploring the context of female delinquents and risk should work to disentangle the impact of these varying interrelated factors and investigate the potential for syndemic effects germane to female delinquency (see [54] for a discussion of the syndemic process).

We found that substance abuse problems increase the odds of an assault referral. Other studies have found that drug use is associated with criminality, and that services can effectively reduce recidivism for serious offenders. However, studies also show that delinquents often do not receive the care they need in residential and community settings [55]. One possibility, beyond the scope of our study, is that young women may be particularly underserved if treatment centers lack beds or program slots for girls and young women, a phenomenon evident in juvenile detention, which has historically been tailored to serve males [56]. In these settings, gender differences may be overlooked delinquent girls may have few intervention programs available [57]. Given the extent and violence accompanying child maltreatment histories of female crossover youth, the field has seen a growing awareness of the need to develop viable trauma-focused treatment for young female offenders. Recent studies demonstrate a range of treatment modalities for addressing the enduring effects of child maltreatment and accompanying relevant comorbid conditions. Evidence suggests that trauma-focused cognitive-behavioral treatment shows special promise for some girls and young women [58-61]. This treatment approach, however, has not yet been studied in its application to crossover youth, and in fact, few studies have demonstrated the effectiveness of cognitive-behavioral treatment generally with adjudicated youth in a restricted setting, such as detention [62]. Future research should explore whether this modality extends its effectiveness for this particularly challenging population.

One finding that is somewhat at odds with other scholarship is that out-of-home placement history decreased the odds of having an assault referral in our sample. Other studies have shown group home placements to be associated with offending and assaults [63,64], though researchers have not examined female populations specifically. It is possible that girls have different experiences in congregate care, and that the conflicts that arise in these settings that lead boys to face assault charges take on a different, less physical forms for girls; biological differences and social norms may lead to less externalizing behavior, or to verbal assaultive behaviors that are less likely to trigger referrals to law enforcement. Being prone to internalizing behaviors may also explain the surprising finding that girls in this study exhibiting mental health disorders and school behavior problems were less likely to engage in violence than other female offenders.

Another surprising finding was that girls with incarcerated parents were somewhat less likely to engage in violence. The loss of parental support and financial resources is likely to increase family stress, 
which can be associated with violence. However, it is also possible that the removal of a dysfunctional parent may also act instead to reduce risks associated with increased violence. Additional research should explore this and other surprising findings in this study, and further identify sources of heterogeneity among female offenders.

Scholars have found that courts, probation, and detention programs are often ill-suited to the girls and young women who come to the attention of law enforcement $[65,66]$. Some research suggests that girls receive distinct processing throughout the justice process, often to their detriment [67]. Understanding how different systems of care interact to identify and serve young people may be especially important; for older youths from troubled families, previous contact with child protection agencies may lead authorities to forego pressing delinquency charges if the child is seen as already receiving needed services from the state's child welfare agency. Similarly, some scholarship suggests that legal personnel have some discretion in filing for dependency or delinquency jurisdiction if a young offender is also found to have been abused or neglected [68]. That is, the association observed between maltreatment history and offending may be biased, given the interaction between offender traits, professional decision making, and institutional constraints. These dynamics, moreover, may be different for boys, girls and different for other subgroups as well.

This study's findings were limited by the constraints of the data available, which are cross-sectional and lacking detail in some key variables. It is also drawn from one state, whose local context may affect the identification and processing of young female offenders. Missouri has a state-run child welfare system and a state juvenile corrections agency that is generally recognized as progressive, while offenders are adjudicated at county courts that vary in practice. Other states' institutional arrangements and local practices will undoubtedly affect how juvenile delinquency is addressed. However, the dataset, albeit from one state, is large enough to allow for exploration of the heterogeneity within the female offender population, something the field currently lacks. Future research will need to push beyond our analyses to explore how the traits, processes, and histories associated with criminal and delinquent behavior specifically affect how girls and young women are processed and changed, such as by the experiences of residential placement and stigmatization [69]. Other studies should also deepen our understanding of how sexual identity [45], race, and ethnicity [70,71] intersect with gender roles in the justice system. Only with additional awareness of the characteristics and needs of females who offend, and how they respond to state intervention distinctly from boys and young men, will the state be able to ensure public safety and serve these vulnerable young people.

\section{Conclusions}

The increasing proportion of girls in the US juvenile justice system emphasizes the need to deepen our understanding of the causes of correlates of their delinquency. Using a state-wide assessment data, this study adds to a small but growing literature on female delinquency, and takes a step towards identifying models that predict subsequent violent behavior. Our findings indicate a statistically significant but weak correlation between violent behavior and childhood maltreatment. However, the relationships among delinquent behavior, maltreatment, involvement in the child welfare system, and other variables explored here are likely to be complicated. Further research is essential to expand our knowledge and to inform services directed at young women who come to the attention of state authorities. 


\section{Author Contributions}

Anne Dannerbeck Janku conceived and designed the article, provided materials, conducted the statistical analysis, and wrote sections; Clark Peters wrote sections of the article, provided materials, and edited article drafts; Jacob Perkins provided additional text for the implications section, provided materials, and edited article drafts.

\section{Conflicts of Interest}

The authors declare no conflict of interest.

\section{References}

1. Tanenhaus, David S. Juvenile Justice in the Making. New York: Oxford University Press, 2004.

2. Peters, Clark M. "Social Work and Juvenile Probation: Historical Tensions and Contemporary Convergences.” Social Work 56 (2011): 355-65.

3. Knupfer, Ann Meis. "Professionalizing Probation Work in Chicago, 1900-1935." Social Service Review 73 (1999): 479-95.

4. Puzzanchera, Charles, and Sarah Hockenberry. Juvenile Court Statistics 2010. Pittsburgh: National Center for Juvenile Justice, 2013.

5. MacDonald, John, and Meda Chesney-Lind. "Gender Bias and Juvenile Justice Revisited: A Multiyear Analysis." Crime \& Delinquency 47 (2001): 173-95.

6. Fontaine, Nathalie, René Carbonneau, Frank Vitaro, Edward D. Barker, and Richard E. Tremblay. "Research Review: A Critical Review of Studies on the Developmental Trajectories of Antisocial Behavior in Females." Journal of Child Psychology and Psychiatry, and Allied Disciplines 50 (2009): 363-85.

7. Kempf-Leonard, Kimberly, Paul Tracy, and James Howell. "Serious, Violent, and Chronic Juvenile Offenders: The Relationship of Delinquency Career Types to Adult Criminality." Justice Quarterly 18 (2001): 449-78.

8. Howell, James C. Preventing \& Reducing Juvenile Delinquency: A Comprehensive Framework. Thousand Oaks: Sage Publications, 2003.

9. Odgers, Candice L., Terrie E. Moffitt, Jonathan M. Broadbent, Nigel Dickson, Robert J. Hancox, Honalee Harrington, Richie Poulton, Malcolm R. Sears, W. Murray Thomson, and Avshalom Caspi. "Female and Male Antisocial Trajectories: From Childhood Origins to Adult Outcomes." Development and Psychopathology 20 (2008): 673-716.

10. Jennings, Wesley G., and Jennifer M. Reingle. "On the Number and Shape of Developmental/ Life-Course Violence, Aggression, and Delinquency Trajectories: A State-of-the-Art Review." Journal of Criminal Justice 40 (2012): 472-89.

11. Chesney-Lind, Meda, and Randall G. Shelden. Girls, Delinquency, and Juvenile Justice. Chichester: John Wiley \& Sons, 2014.

12. Puzzanchera, Charles. Juvenile Arrests 2011. Washington, D.C.: Office of Juvenile Justice and Delinquency Prevention (OJJDP), U.S. Department of Justice, 2013. 
13. Dixon, Jo. "Mandatory Domestic Violence Arrest and Prosecution Policies: Recidivism and Social Governance." Criminology \& Public Policy 7 (2008): 663-70.

14. Deleon-Granados, William, William Wells, and Ruddyard Binsbacher. "Arresting Developments: Trends in Female Arrests for Domestic Violence and Proposed Explanations." Violence against Women 12 (2006): 355-71.

15. Dannerbeck, Anne, Paul Sundet, and Kathy Lloyd. "Drug Courts: Gender Differences and their Implications for Treatment Strategies." Corrections Compendium 27 (2002): 1-10.

16. Nelson-Zlupko, Lani, Eda Kauffman, and Martha Morrison Dore. "Gender Differences in Drug Addiction and Treatment: Implications for Social Work Intervention with Substance-Abusing Women." Social Work 40 (1995): 45-54.

17. Davis, Carla P. "At-risk Girls and Delinquency: Career pathways." Crime \& Delinquency 53 (2007): 408-35.

18. Bosworth, Mary. "Confining Femininity: A History of Gender, Power and Imprisonment." Theoretical Criminology 4 (2000): 265-84.

19. Ericsson, Kjersti, and Nina Jon. "Gendered Social Control: 'A Virtuous Girl' and 'A Proper Boy'." Journal of Scandinavian Studies in Criminology and Crime Prevention 7 (2006): 126-41.

20. Morgan, Betsy Levonian. “A Three Generation Study of Tomboy Behavior.” Sex Roles 39 (1998): 787-800.

21. Finkelhor, David, and Jennifer Dziuba-Leatherman. "Victimization of Children." American Psychologist 49 (1994): 173-83.

22. Eddy, J. Mark, and John B. Reid. The Antisocial Behavior of the Adolescent Children of Incarcerated Parents: A Developmental Perspective. Washington, D.C.: Urban Institute \& US Department of Health and Human Services, 2001.

23. Hagan, John, John H. Simpson, and A. R. Gillis. "The Sexual Stratification of Social Control: A Gender-Based Perspective on Crime and Delinquency." The British Journal of Sociology 30 (1979): 25-38.

24. Fishbein, Diana H., and Deanna M. Pérez. "A Regional Study of Risk Factors for Drug Abuse and Delinquency: Sex and Racial Differences." Journal of Child and Family Studies 9 (2000): 461-79.

25. Miller, Jody. One of the Guys: Girls, Gangs, and Gender. New York: Oxford University Press, 2001.

26. Howell, James C. "Youth Gangs: Prevention and Intervention." In Intervention with Children and Adolescents: An Interdisciplinary Perspective, 2nd ed. Edited By Paula Allen-Meares and Mark W. Fraser. Boston: Allyn \& Bacon, 2003, pp. 493-514.

27. Siegel, Jane, and Linda Williams. "The Relationship between Child Sexual Abuse and Female Delinquency and Crime: A Prospective Study." Journal of Research in Crime and Delinquency 40 (2003): 71-94.

28. Ireland, Timothy, Carolyn A. Smith, and Terence P. Thornberry. "Developmental Issues in the Impact of Child Maltreatment on Later Delinquency and Drug Use." Criminology 40 (2000): 359-400.

29. Widom, Cathy S., and Michael G. Maxfield. An Update on the "Cycle of Violence". Washington, D.C.: National Institute of Justice, 2001.

30. Kendall-Tackett, Kathleen A., Linda M. Williams, and David Finkelhor. "Impact of Sexual Abuse on Children: A Review and Synthesis of Recent Empirical Studies." Psychological Bulletin 113 (1993): 164-80. 
31. Kaufman, Jeanne G., and Cathy S. Widom. "Childhood Victimization: Running Away and Delinquency." Journal of Research in Crime and Delinquency 36 (1999): 347-70.

32. Datesman, Susan K., and Frank R. Scarpitti. "Female Delinquency and Broken Homes: A Reassessment." Criminology 13 (1975): 33-35.

33. Norland, Stephen, Neal Shover, William E. Thornton, and Jennifer James. "Intrafamily Conflict and Delinquency." Pacific Sociological Review 22 (1979): 223-40.

34. Crosson-Tower, Cynthia. Exploring Child Welfare: A Practice Perspective. Boston: Allyn and Bacon, 2004.

35. Crick, Nicki R., and Jennifer K. Grotpeter. "Relational Aggression, Gender, and Social-Psychological Adjustment." Child Development 66 (1995): 710-22.

36. Acoca, Leslie. "Investing in Girls: A 21st Century Strategy." Juvenile Justice 6 (1999): 3-13.

37. Funk, Stephanie J. "Risk Assessment for Juveniles on Probation: A Focus on Gender." Criminal Justice and Behavior 26 (1999): 44-68.

38. Wardenski, Joseph J. "A Minor Exception?: The Impact of Lawrence v. Texas on LGBT Youth." The Journal of Criminal Law and Criminology 95 (2005): 1363-410.

39. Dannerbeck, Anne, and Jiahui Yan. "Missouri's Crossover Youth: Examining the Relationship between Their Maltreatment History and Their Risk of Violence." Journal of Juvenile Justice 1 (2011): 77-96.

40. Leonhard, Kimberly. Missouri Risk Assessment and Classification Project Report. Jefferson City: Office of State Courts Administrator, 1998.

41. Johnson, Kristen, Dennis Wagner, and Tim Matthews. Missouri Juvenile Risk Assessment Re-Validation Report. Madison: National Council on Crime and Delinquency, 2002.

42. McElfresh, Rick A. Missouri Juvenile Risk Assessment Re-Validation Report. Jefferson City: Office of State Courts Administrator, 2011.

43. National Council on Crime and Delinquency. Development of an Empirically-Based Risk Assessment Instrument and Placement Recommendation Matrix, Final Report. Washington, D.C.: National Council on Crime and Delinquency, 1997.

44. Missouri Office of State Courts Administrator. Juvenile Offender Risk and Needs Assessment and Classification System. Jefferson City: Missouri Office of State Courts Administrator, 2005.

45. Fitzgerald, Robin. Parenting, School Context, and Violent Delinquency. Ottawa: Canadian Center for Justice Statistics, 2010.

46. Dannerbeck, Anne. "Differences in Parenting Attributes of Youth With and Without a Parental Incarceration History.” Youth Violence and Juvenile Delinquency 3 (2005):199-213.

47. Bloom, Barbara, Barbara Owen, and Stephanie Covington. Gender-Responsive Strategies: Research, Practice, and Guiding Principles for Women Offenders. Washington, D.C.: National Institute of Justice, 2003.

48. Howell, James C. Preventing and Reducing Juvenile Delinquency. Thousand Oaks: Sage Publications, 2009.

49. Cohen, Jacob, Patricia Cohen, Stephen West, and Leona Aiken. Applied Multiple Regression/Correlation Analysis for the Behavioral Sciences. London: Lawrence Erlbaum Associates, 2003. 
50. Ryan, Joseph P., Denise Herz, Pedro M. Hernandez, and Jane Marie Marshall. "Maltreatment and Delinquency: Investigating Child Welfare Bias in Juvenile Justice Processing." Children and Youth Services Review 29 (2007): 1035-50.

51. Drake, Brett, Sang Moo Lee, and Melissa Jonson-Reid. "Race and Child Maltreatment Reporting: Are Blacks Overrepresented?" Children and Youth Services Review 31 (2009): 309-16.

52. Mallett, Christopher A. "Youthful Offending and Delinquency: The Comorbid Impact of Maltreatment, Mental Health Problems, and Learning Disabilities." Child and Adolescent Social Work Journal 31 (2014): 369-92.

53. Kenny, Diana T., Susan Blacker, and Mark Allerton. "Reculer Pour Mieux Sauter: A Review of Attachment and Other Developmental Processes Inherent in Identified Risk Factors for Juvenile Delinquency and Juvenile Offending." Laws 3 (2014): 439-68.

54. Singer, Merrill. Introduction to Syndemics. San Francisco: Jossey-Bass, 2009.

55. Shubert, Carol A., and Edward P. Mulvey. Behavioral Health Problems, Treatment, and Outcomes in Serious Youthful Offenders. Washington, D.C.: Office of Juvenile Justice and Delinquency Prevention, 2014.

56. Chesney-Lind, Meda, Merry Morash, and Tia Stevens. "Girls' Troubles, Girls' Delinquency, and Gender Responsive Programming: A Review." Australian and New Zealand Journal of Criminology 41 (2008): 162-89.

57. Brumbaugh, Susan, Jennifer L. Walters, and Laura A. Winterfield. Suitability of Assessment Instruments for Delinquent Girls. Washington, D.C.: US Office of Juvenile Justice and Delinquency Prevention, 2008.

58. Cary, Colleen E., and J. Curtis McMillen. "The Data behind the Dissemination: A Systematic Review of Trauma-Focused Cognitive Behavioral Therapy for Use with Children and Youth." Children and Youth Services Review 34 (2012): 748-57.

59. Cohen, Judith, Anthony P. Mannarino, Lucy Berliner, and Esther Deblinger. "Trauma-Focused Cognitive Behavioral Therapy for Children and Adolescents: An Empirical Update." Journal of Interpersonal Violence 15 (2000): 1202-23.

60. Leenarts, Laura E. W., Julia Diehle, Theo A. H. Doreleijers, Elise P. Jansma, and Ramón J. L. Lindauer. "Evidence-Based Treatments for Children with Trauma-Related Psychopathology as a Result of Childhood Maltreatment: A Systematic Review." European Child \& Adolescent Psychiatry 22 (2013): 269-83.

61. Skowron, Elizabeth, and Dawn H. S. Reinemann. "Effectiveness of Psychological Interventions for Child Maltreatment: A Meta-Analysis.” Psychotherapy: Theory, Research, Practice, Training 42 (2005): 52-71.

62. Bengt-Åke Armelius, and Tore Henning Andreassen. "Cognitive-Behavioral Treatment for Antisocial Behavior in Youth in Residential Treatment." The Cochrane Database of Systematic Reviews 4 (2007): CD005650.

63. Jonson-Reid, Melissa, and Richard P. Barth. "From Placement to Prison: The Path to Adolescent Incarceration from Child Welfare Supervised Foster or Group Care." Children and Youth Services Review 22 (2000): 493-516. 
64. Ryan, Joseph P., Jane Marie Marshall, Denise Herz, and Pedro M. Hernandez. "Juvenile Delinquency in Child Welfare: Investigating Group Home Effects." Children and Youth Services Review 30 (2008): 1088-99.

65. Acoca, Leslie. "Are Those Cookies for Me or My Baby? Understanding Detained and Incarcerated Teen Mothers and Their Children.” Juvenile \& Family Court Journal 55 (2004): 64-80.

66. Cynthia M. Conward. "Where Have All the Children Gone? A Look at Incarcerated Youth in America." William Mitchell Law Review 27 (2001): 2435-99.

67. Smith, Wendy B. Youth Leaving Foster Care: A Developmental, Relationship-Based Approach to Practice. New York: Oxford University Press, 2011.

68. Peters, Clark M. "Examining Regional Variation in Extending Foster Care beyond 18: Evidence from Illinois." Children and Youth Services Review 34 (2012): 1709-19.

69. Andrew James McGrath. "The Subjective Impact of Contact with the Criminal Justice System: The Role of Gender and Stigmatization." Crime \& Delinquency 60 (2014): 884-908.

70. Michael J. Leiber, Joseph Johnson, Kristan Fox, and Robyn Lacks. "Differentiating among Racial/Ethnic Groups and its Implications for Understanding Juvenile Justice Decision Making." Journal of Criminal Justice 35 (2007): 471-84.

71. Leve, Leslie D., and Patricia Chamberlain. "Female Juvenile Offenders: Defining an Early-Onset Pathway for Delinquency." Journal of Child and Family Studies 13 (2004): 439-52.

(C) 2014 by the authors; licensee MDPI, Basel, Switzerland. This article is an open access article distributed under the terms and conditions of the Creative Commons Attribution license (http://creativecommons.org/licenses/by/4.0/). 